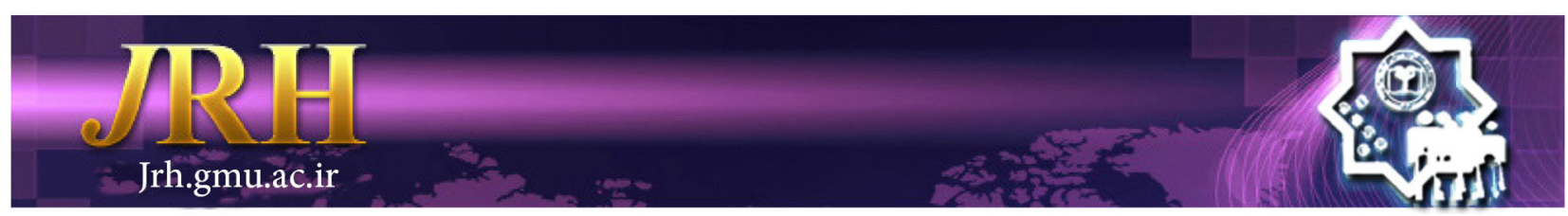

\title{
Effect of daily life executive functions training on symptoms and adaptive skills in children with attention deficit/ hyperactivity disorder
}

Seyedeh Roghayeh Noorani Jurjadeh ${ }^{1}$, Ali Mashhadi ${ }^{1}$, Zahra Tabibi ${ }^{1}$, Farzan Kheirkhah ${ }^{2}$

\author{
Journal of Research \& Health \\ Social Development \& Health Promotion \\ Research Center \\ Vol. 8, No. 3, May \& Jun 2018 \\ Pages: $269-277$ \\ DOI: $10.29252 / j r h .8 .3 .269$ \\ Original Article
}

1. Department of Clinical Psychology, Faculty of Education Sciences and Psychology, Ferdowsi University of Mashhad, Mashhad, Iran

2. Department of Psychiatry and Neurology, School of Medicine, Babol University of Medical Sciences, Babol, Iran

Correspondence to: Ali Mashhadi, Department of Clinical Psychology, Faculty of Education Sciences and Psychology, Ferdowsi University of Mashhad, Mashhad, Iran

Email: mashhadi@um.ac.ir

Received: 10 Jan 2016

Accepted: 8 Nov 2016

How to cite this article: Noorani Jurjadeh SR, Mashhadi A, Tabibi Z, Kheirkhah F. Effectiveness of executive functions training based on daily life on reduce symptoms and improve adaptive skills in children with attention deficit/ hyperactivity disorder. $J$ Research Health2018; 8(3): 269- 277.

\begin{abstract}
Attention Deficit/Hyperactivity Disorder (ADHD) is a neurodevelopmental disorder which was diagnosed by three features including: attention deficit, hyperactivity and impulsivity. This study aimed to determine the effect of executive function training based on daily life on reducing symptoms and improving adaptive skills in children with ADHD. 16 children aged 7-10 years old with ADHD were selected by random sampling method from clients of the department of psychiatry in Babol hospital and were divided randomly into experimental and control groups $(n=8)$. Subjects were assessed in two steps at pretest and posttest by SNAP-IV and Barkley Functional Impairment Scale Children and Adolescents (BFIS-CA). The intervention group received 11 training sessions (1 hour in each session) with their mothers. The research findings showed that subjects of the experimental group had significant reduction in posttest scores of SNAP-IV scale than the control group. Significant reduction was observed in the scores of BFIS scale in the experimental group for both Homeschool impairment and Community-Leisure impairment subtests. According to findings executive function training based on daily life leads to reduce ADHD symptoms and improve adaptive skills in children with ADHD. It is concluded that executive functions training based on daily life for ease of use and the applicability of its methods can be used in different situations such as home and school for reducing symptoms and improving adaptive skills in children with ADHD.
\end{abstract}

Keywords: ADHD, Adaptation, Executive, Function, Psychological

\section{Introduction}

According to the Diagnostic and Statistical Manual of Mental Disorders-5 (DSM5) important feature of Attention Deficit/ Hyperactivity Disorder (ADHD) is stable pattern of attention deficit/hyperactivity impulsivity which interferes with personal function and evolution and also occurs before age 12. It has three subtypes: ADHD predominantly inattentive subtype (ADHD-I), ADHD predominantly hyperactive/impulsive subtype (ADHD-H) and ADHD combined subtype (ADHD-C). Study of demographic features showed that prevalence rate of ADHD is about $5 \%$ in children and $5.2 \%$ in adults 
in most cultures [1]. The overall prevalence of this disorder have been reported $11.4 \%$ in Iran [2]. So, Attention Deficit/Hyperactivity Disorder (ADHD) is important because of its consequences. It not only causes difficulties in childhood of patients, but also in most cases affects their whole lives and costs too much for the society [3]. It has been a long time that this disorder has been known with impaired executive functions. The cognitive pattern which associates impaired executive function with behavioral symptoms of ADHD has three main symptoms of ADHD (hyperactivity, attention deficit and impulsivity) that all are subsets failure in inhibition (which is type of executive functions) $[4,5]$. Study was conducted to assess executive functions in children with ADHD that stated different symptoms in different individuals is because of the deficit level in their executive function [6]. Also, there are other studies which reported children with Attention Deficit/Hyperactivity Disorder (ADHD) experience changes in many important structural components include inhibition, sustained attention, working memory, abstract thinking and performance planning [7-11]. Executive functions are self-command actions which are used for self-control and the targeted behavior [4]. These functions cover the skills that are defined as activities such as sustainable attention during doing homework, homework decisions, planning and organizing the tasks, self-initiation and needed flexibility to achieve own goals [12]. Failure in these functions in children with ADHD emerges symptoms such as impulsive act, amnesia, lack of sustained concentration and attention, failure to comply with the program and failure of self-regulation of affect, etc. Subsequent failure occurs in psychosocial impairment skills. These children compared with their normal peers are less likely to have ability to identify environmental components of emotional messages from its informative components, to use the revision and foresight for behavioral control, to use the inner voice in order to guide their behavior and to analyze and synthesize the different aspects of the environment [13]. They have impaired executive functions in daily life such as relationships with parents, siblings, peers and inabilities such as self-care, selfprotection and education competence which is expected from children of different ages [14]. Thus, theory of executive functions in the pathology and treatment of ADHD is important theory. Hence, in recent decades, in addition to pharmacotherapy, educational and psychosocial interventions and treatments have been considered for ADHD but the empirical support based interventions are more important. In review study which examined empirically supported psychosocial interventions from 2008 to 2013 in the field of ADHD, psychosocial interventions were divided into two general categories of Behavioral Management (BM) and Training Interventions (TI). The Behavioral Management (BM) category includes interventions which perform to moderate and modify the environment of children with ADHD; offered training to parents, teachers and peers are these types. The Training Intervention (TI) includes those interventions that occur in the children with ADHD including neurofeedback, cognitive training (training of working memory, attention and executive functions) and organization skills training [15]. Among the educational programs applied in the field of executive functions, we can refer to computer programs for working memory in children with Attention Deficit/Hyperactivity Disorder (ADHD). In this computer program, the span board and the visual-spatial were tasked to teach and strengthen the working memory. The results of this study showed that this computer program can improve working memory in children and also can increase the response inhibition and reasoning of these children [16]. Another research investigated the effects of working memory training computer program on attention and working memory in children with Attention Deficit/ Hyperactivity Disorder (ADHD) and learning disabilities. Its results showed that the educational software had significant impact 
on cognitive flexibility and working memory [17]. In another study, the researchers used the computerized cognitive training methods to improve the executive functions in children with ADHD. Training consisted of 25 sessions of 3040 minutes which were conducted at their homes and parents monitored their children. When the child completed the computer sessions, they would give reward the child. In the end, parents and teachers filled the measurement scales. Parents reported the effectiveness of training in the 10 components of executive functions while the teachers reported the improvement in only one of the components. One reason for the difference between the parents' reports and teachers' reports was described in the parent's awareness of treatment process [18]. There are some other research in this area that include cognitive-promoting software [19], attention training program [20,21], rehabilitation of inhibition executive function [22], working memory training [23] and the inhibition executive function training through games [24]; Inhibition executive function training, planning and organizing based on narrative therapy [25] and dozens of other studies have proved the effectiveness of executive function training on improving functions and symptoms of ADHD. Educational and therapeutic programs can be more successful when they are more effective to act simultaneously on both the environment and personal levels and consider different dimensions of disorder. So considering the importance of role of executive functions deficit in etiology of the ADHD and deficit in adaptive skills in children with ADHD [4-11,13,14] as well as effectiveness of various training programs in improving executive functions and reducing symptoms [16-25], using executive function training method with ease of implementation and usable in different situations would be necessary. In this regard, the present study sought to evaluate the effectiveness of executive function training based on daily life which was designed by Dawson and Guare in 2010 in children with ADHD. Difference between this training and previous programs is that unlike other educational practices that are often in software this is practical training in the context of daily life and therefore provides more useful features for parents, teachers and friends of children with ADHD. The features of this program are in two levels of child and environmental interventions thus we can state that it has benefits to both the psychosocial interventions of Behavioral Management (BM) and Training Interventions (TI)and individually act for two etiological factors of ADHD, i.e. the environmental and neurobiological factors. According to mentioned functional features for this method, this study aimed to determine the effectiveness of executive function training based on daily life on reducing symptoms and improving adaptive skills in children with ADHD.

\section{Method}

This study is a quasi-experimental research and pretest-posttest with control group. The population study includes children with ADHD who referred to Department of Psychiatry in Shahid Yahyanejad Hospital in Babol, Mazandaran since November 2013 to March 2014.

Sample size was estimated 8 children in each group based on $\mathrm{G}$ power software program for 2 groups of experimental and control groups. The sample size consisted of 16 children aged 7 to 10 years old with ADHD who were not on medication and were selected by purposive sampling and randomly were assigned to 2 experimental and control groups $(n=8)$. The inclusion criteria were ADHD combined subtype (ADHD-C) diagnosis, between 7-10 year-old, lack of medication and lack of participation of any other educational program or cognitive interventions in parallel of present study and exclusion criteria were predominantly inattentive subtype (ADHD-I) and predominantly hyperactive/impulsive subtype (ADHD-H) diagnosis, higher or lower than 7-10 years age, receive medication and participation of any educational program or cognitive interventions in in parallel of present study. The experimental group received 11 sessions of executive functions 


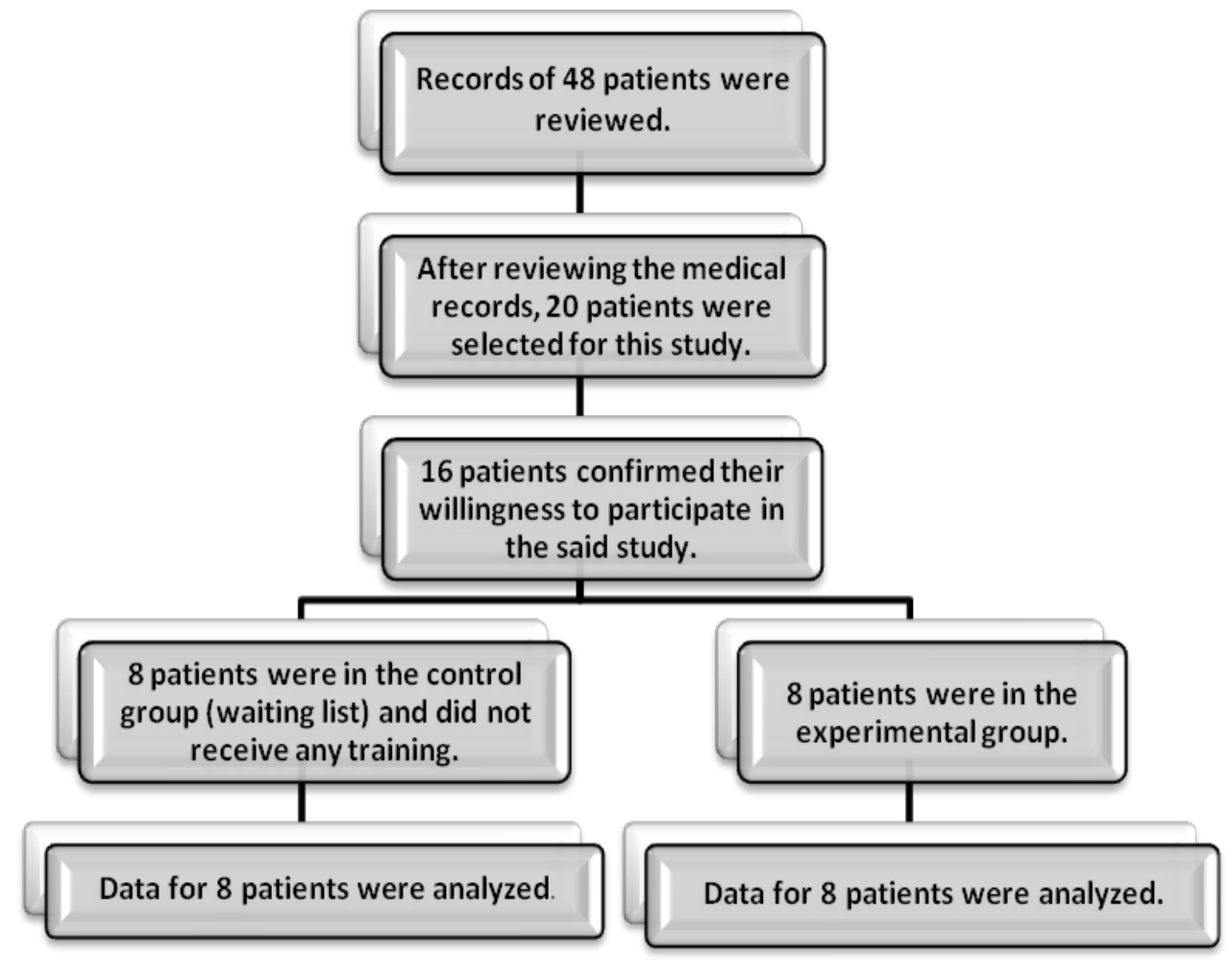

Chart 1 Information for participants

Data were collected by using Clinical interview, SNAP-IV Grading scale and Barkley Functional Impairment Scale- Children and Adolescents (BFIS-CA).

Clinical interview: Clinical interviews are the basis for important multidimensional measure system for ADHD which in this study was conducted by children specialists and adolescent psychiatrist.

SNAP-IV Grading scale: This scale was established for the first time by Swanson, Nolan and Pelham in 1980 to assess the symptoms of ADHD. The scale has single form of 18 items for parents and teachers that the first 9 items identify ADHD-I and the second 9 items identify ADHD-H. All the 18 items are used to identify ADHD-C. Grading or responding was done based on a Likert scale from 0 to 3 ranges. The total validity of this scale has been reported $97 \%$ and for the subtypes $90 \%$ and $79 \%$ [26]. In Iran, also reliability coefficient of scale by using the test-retest, Cronbach's alpha coefficient and split-half coefficient has been reported $82 \%, 90 \%$ and $76 \%$, respectively
[27]. In the present study, this scale was used to assess the symptoms of ADHD.

Barkley Functional Impairment ScaleChildren and Adolescents (BFIS-CA): BFIS-CA provides clinical data to assess psychosocialadaptationskillsindailyactivities for children ages 6 to 17 years old according parents' reports. This scale was developed in 2011 by Barkley. The scale has two parts. The first part evaluates the impairment in 15 areas of major life activities in which there are 9 areas of the Home-School factors and 6 areas of Community-Leisure factors; the second part includes 8 items about the impairment related to community, society and school. There is strong evidence that confirms the reliability, validity and usefulness of this scale to measure psychosocial adjustment skills of children and adolescents in the daily life activities. Reported Cronbach's alpha for the total scale, the home-school factor, and the community-leisure factor were reported 0.97, 0.94 and 0.96 respectively. Reliability of test - retest was high for both the scales. Based on 
evidence, this scale has face validity and is also sufficient criterion. The correlation factor was obtained 0.82 between the home-school and community-leisure dimensions [14].

Due to fact that the Barkley Functional Impairment Scale has not been performed on the Iranian population so it's psychometric properties were examined. The internal consistency method (Cronbach's alpha) was used to evaluate the reliability of the questionnaire. Cronbach's alpha coefficient of the questionnaire was obtained 0.85 after reviewing data from a sample of children with ADHD. The internal consistency of home-school and communityleisure subscales was calculated 0.74 and 0.73 . This scale was used in the pretest to assess impairment in ADHD adaptive skills and in the posttest to measure the effectiveness of the treatment to improve these skills.

Data analysis was conducted by using SPSS-19 in both parts. The first part is devoted to the descriptive findings, in these stages the statistical indicators, such as mean and standard deviation were used. In the second part, the analysis of univariate covariance (ANCOVA) and analysis of multiple covariance (MANCOVA) methods were used to test the hypothesis of the research. The study was conducted in several steps. Prior to starting, informed consent was obtained from parents of participants in the scheme. At the first step of the study, after diagnosed by psychiatrist, the BFIS and SNAP-IV scales were completed by mothers. In the second step, the experimental group participated in the 11 one-hour session (30 minutes child and 30 minutes parent) that consist of two-training sessions for the parent and 9 joint parentchild training sessions once week. In the first session, after the initial communication, the process and what is going to happen would be explained. A list of problematic behaviors in children was prepared and after determining whether any behavior or sometimes problematic behaviors caused the deficit of any executive functions, educational priorities, clear behavioral goals and whatever behaviors supposed to be treated will be determined in each session. In subsequent sessions, after reviewing and evaluating the strategies used in the past week, the required training would be assigned in relation to the executive functions, interventions and changes that need to be happened in the environment. A total of 88 hours (11 hours for each subject) was done within 11 weeks. In the third step and after 11 sessions, during separate session, the mothers of both the control and experimental groups were asked to go to the clinic for the posttests. Finally, training sheets were given to the mothers in whom the management of executive functions was indicated in a detailed chart.

\begin{tabular}{cl}
$\begin{array}{l}\text { Table } 1 \text { The protocol of executive functions training based on daily } \\
\text { life activities }\end{array}$ \\
\hline Session & Session's plan \\
\hline $1^{\text {st }}$ & Meet the mother and explain the process sessions \\
$2^{\text {nd }}$ & Self-control training \\
$3^{\text {rd }}$ & Evaluation and generalization \\
$4^{\text {th }}$ & Self-regulation of affect training \\
$5^{\text {th }}$ & Evaluation and generalization \\
$6^{\text {th }}$ & Self-motivation training \\
$7^{\text {th }}$ & Evaluation and generalization \\
$8^{\text {th }}$ & Self-organizing training \\
$9^{\text {th }}$ & Evaluation and generalization \\
$10^{\text {th }}$ & Time Management training \\
$11^{\text {th }}$ & Evaluation and generalization \\
\hline
\end{tabular}

\section{Results}

Table 2 shows the mean and standard deviation

of ADHD-C scores of SNAP-IV scale for 
both the pre test and post test.

As Table 2, the experimental group compared to the control group achieved lower mean score of ADHD-C in post test. The analysis of univariate covariance was used to determine the significance of the differences.

\begin{tabular}{ccccc}
\multicolumn{4}{c}{ Table 2 Descriptive statistics of ADHD-C scores of subjects in SNAP-IV grading scale } \\
\hline $\begin{array}{c}\text { Dependent } \\
\text { Variable }\end{array}$ & Time & Group & Mean & SD \\
\hline \multirow{3}{*}{ ADHD-C } & \multirow{2}{*}{ Pretest } & Experimental & 34.38 & 6.71 \\
\cline { 2 - 5 } & & Control & 34.50 & 6.78 \\
\hline \multirow{2}{*}{ Posttest } & Experimental & 15.88 & 6.89 \\
& & Control & 3588 & 6.35 \\
\hline
\end{tabular}

It should be noted before the univariate analysis and multivariate analysis of covariance, the presuppositions variable such as normal distribution, variances homogeneity of variables in 2 groups and coherence slope of the regression line were examined. The KolmogorovSmirnov test showed that variable distribution is normal $(\mathrm{p}>0.05)$. Levene's test in variables were not significant $\left(\mathrm{F}_{(1,14)}=2.86 \& \mathrm{p}>0.05\right)$ which indicates same variance in both the experimental and control groups. Also the slope of the regression line shows the homogeneity of it in two groups $\left(\mathrm{F}_{(1,12)}=3.84 \& \mathrm{p}>0.05\right)$.

Table 3 shows that the pretest scores of ADHD-C of SNAP-IV rating scale had no significant effect during the posttest $\left(\mathrm{F}_{(1,13)}=\right.$ 3.32 and $\mathrm{p}>0.05$ ). After controlling the pretest scores, the effect of group for posttest was significant $\left(\mathrm{F}_{(1,13)}=42.18\right.$ and $\mathrm{p}<0.001$ Partial $\eta 2=0.76)$. Thus, the experimental group compared to the control group was significantly reduced at posttest ADHD-C scores.

Table 3 Tests of between subjects effects in executive functions training based on daily life group on the ADHD-C

\begin{tabular}{clccccc}
\hline \multirow{2}{*}{ Source } & $\begin{array}{l}\text { Dependent } \\
\text { variable }\end{array}$ & Sum of Square & df & Mean of Square & F & Partial Eta \\
\hline \multirow{2}{*}{ ADHD-C } & Pretest & 125.44 & 1 & 125.44 & 3.32 & 0.20 \\
& Group & 1590.98 & 1 & 1590.98 & $42.18^{*}$ & 0.76 \\
& Error & 490.30 & 30 & 13 & & \\
$* \mathrm{p}<0.01$ & & & &
\end{tabular}

Table 4 shows the mean and standard deviation of home-school (HS) and community-leisure scores $(\mathrm{CH})$ of BFIS scale.

Table 4 shows that the mean scores of the experimentalgroupforhome-schoolimpairment and community-leisure impairment in the posttest decreased compared to the pretest, whereas the mean score in the control group increased in the posttest compared to the pretest.

Table 4 Descriptive statistics on the mean scores of home-school impairment and community-leisure impairment of participants based on Barkley functional impairment scale (BFIS)

\begin{tabular}{|c|c|c|c|c|c|c|c|c|}
\hline \multirow{3}{*}{ Group } & \multicolumn{4}{|c|}{ Experimental } & \multicolumn{4}{|c|}{ Control } \\
\hline & \multicolumn{2}{|c|}{ Pre Test } & \multicolumn{2}{|c|}{ Post Test } & \multicolumn{2}{|c|}{ Pre Test } & \multicolumn{2}{|c|}{ Post Test } \\
\hline & $\mathrm{M}$ & SD & $\mathrm{M}$ & SD & $\mathrm{M}$ & $\mathrm{SD}$ & $\mathrm{M}$ & $\mathrm{SD}$ \\
\hline $\begin{array}{l}\text { Home-School } \\
\text { Impairment }\end{array}$ & 4.25 & 1.28 & 2.13 & 1.22 & 4.21 & 0.66 & 4.26 & 0.59 \\
\hline $\begin{array}{l}\text { Community- } \\
\text { Leisure Impairment }\end{array}$ & 4.77 & 1.88 & 2.07 & 1.27 & 4.18 & 1.19 & 4.25 & 1.01 \\
\hline
\end{tabular}

Table 5 shows the results of analysis of multivariate covariance between the two groups in the combination of mean scores of home- school impairment and communityleisure impairment that the adaptive skills had significant difference $\left(\mathrm{F}_{(2,11)}=36.68\right.$ and $\mathrm{p}<0.001$; = Pillai's Trace 0.87; Partial $\eta 2=$ 0.87 ). As table 5 , the analysis of each of the dependent variables indicated the score of home-school impairment subscale $\left(\mathrm{F}_{(1,12)}=\right.$ 75.97 and $\mathrm{p}<0.001$ Partial $\eta 2=0.86$ ), and also the score of community- leisure 
impairment subscale $\left(\mathrm{F}_{(1,12)}=19.24\right.$ and $\mathrm{p}<0.001$

Partial $\eta 2=0.61$ ) in the experimental group had a significant reduction in posttest compared to the control group.

Table 5 Tests of between subjects effects in executive functions training based on daily life group on the scores of home-school impairment and community-leisure impairment

\begin{tabular}{clccccc}
\hline Source & Dependent variable & Sum of Square & df & Mean of Square & F & Partial Eta \\
\hline Group & $\begin{array}{l}\text { Home-School } \\
\text { Impairment } \\
\text { Community- }\end{array}$ & 17.79 & 1 & 17.79 & $75.97^{*}$ & 0.86 \\
& Leisure Impairment & 19.82 & 1 & 19.82 & $19.24^{*}$ & 0.61 \\
\hline Error & $\begin{array}{l}\text { Home-School } \\
\text { Impairment } \\
\begin{array}{l}\text { Community- } \\
\text { Leisure Impairment }\end{array}\end{array}$ & 12.36 & 12 & 0.23 & \\
${ }^{*} \mathrm{p}<0.001$ & & & 1.03 &
\end{tabular}

\section{Discussion}

The present study aimed to assess the effectiveness of executive function training based on daily life on reducing symptoms and improving adaptive skills in children with ADHD. Results indicates the effectiveness of executive function training based on daily life on reducing symptoms in children with ADHD.Thus the first hypothesis of research is confirmed so it is consistent with some other studies. Evans, Owens \& Bunford in 2013 showed that one of cognitive training for reducing symptoms of ADHD that have empirical support is executive functions training [15]. Also some other studies showed that executive functions training is effective method for reduce symptoms of ADHD [3,4, 11-13,17-19,21-25].

In this research, the opportunity for further reflection and better planning to achieve the objectives was given to the children by providing challenging assignments and opportunities to improve the executive functions and making changes in environment by providing cues and reminders and modified requests and also parents' accompaniment and supervision. Followed by disproportionate responses to situation and the time interval to return to function would decrease due to the attention of the unfinished distracting stimuli. The therapist paid more attention to the executive functions of time management and organization besides the trainings to focus on their attention, sustained attention, patience and emotional inhibition ability and self-organize to subjects.
Training was done by telling story, painting and crafts, the importance of these actions were developed step by step instructions and paying attention to signs for achieving the goals. While these children in ordinary conditions manifested the executive function impairment in ADHD symptoms after training they had significantly fewer symptoms of this disorder than they had before.

Second hypothesis of this research is the effectiveness of executive function training on improving adaptive skills in children with ADHD. Results revealed that the effectiveness of executive function training on improving adaptive skills in children with ADHD.Thus the second hypothesis of research is confirmed and therefore is consistent with some other studies. Barkley in 2012, Dawson \& Guare in 2010 and Rapoport in 2009 showed that deficit in executive functions has important role in deficit in the social and adaptive skills and executive functions training is effectiveness method for improving them. Some other studies also showed executive functions training has effect on improving adaptive skills in children with ADHD $[6,8,15]$.

Deficit in the social skills of children with ADHD has status that they do not know how to act appropriately or maybe they know good method but do not do it exactly. Such flaws and shortcomings in the social skills of children may annoy their parents, teachers and peers whit these behaviors and supposedly they are not pleasant and may result in neglecting 
or excluding them [28]. Deficit in executive function especially actions such as self-discipline and self-organization for emotional inhibition in children with ADHD largely explains this inconsistency. Children behavior is such that has negative reactions to others as consequences and make vicious circle of reciprocal behavior of child. Consequently, the present study tried to break this vicious circle with training in positive interactions with children and solving problems and making changes in parents and their environment besides executive functions in the child's daily activities. Anticipating the situations were part of training where in the child may have problem. Anticipating these situations has two advantages: First, to allow parents, if possible, modify the environment and second prevent the first answer provided in the child's mind by examination and education possible solutions to child. Therefore, the observed improvement in adaptive skills of children after training was the result of interventions that took place in two individual and the environmental levels. With regard to the applicability of this intervention considerable results can be achieved by training the people involved with ADHD children (parents, siblings, teachers, friends, etc.). Parents and teachers should be very patient in training the appropriate social skills to children with ADHD because learning these skills is long process and chain of necessary social skills to interact positively with others such as eye contact, respect for others, start conversation and other required social skills, using reinforcement and praise, exercises, role play and so on should be taught in these children.

Study limitations included lack of reviews of effectiveness of executive function training on ADHD predominantly inattentive subtype (ADHD-I) and predominantly hyperactive/ impulsive subtype (ADHD-H) on separation and lack of control of comorbid disorders. Since the mother was important members of executive function training process so differences in parent's level of education is another limitation of current study. The present research offers for future using executive function training in school and in collaboration with teachers, to increase sessions and duration of training and then asses the neuropsychological effects of it with brain imaging and asses effect of executive function training in other clinical population include; brain injury, autism spectrum disorder and sleep disorders.

\section{Conclusion}

Executive functions training based on daily life is effective method in reducing symptoms and improving adaptive skills in children with Attention Deficit/ Hyperactivity Disorder (ADHD). This intervention is fully functional method because of ease of use for parents, teachers and other child's relatives. Another advantage of this method is intervention in both level of individual and environment that help to integrate it. Considering that deficit in executive functions is related to frontal lobe function so we can state that the child's relatives can play role of the external frontal lobe by use of executive functions training based on daily life [10].

\section{Acknowledgements}

Hereby, cooperation of Ferdowsi University of Mashhad, Babol University of Medical Sciences, personnels of Shahid Yahyanejad Hospital and participants in this study is highly appreciated.

\section{Contribution}

Study design: SRN, AM

Data collection and analysis: SRN, AM , ZT, FKH

Manuscript preparation: SRN, AM

\section{Conflict of Interest}

"The authors declare that they have no competing interests"

\section{Funding}

The author (s) received no financial support for the research, authorship and/or publication of this article.

\section{References}

1- American Psychiatric Association. Diagnostic and statistical manual of mental disorders-5. Washington, 
DC: Author; 2013.

2- Dashti D, Abolhasani F, Majidzadeh SR, Alaghbandrad

J, Eftekhar H. Attention deficit hyperactivity disorder in Iranian population in 2003. Advances in Cognitive Science 2006; 4:40-56.

3- Barkley RA. Attention-deficit disorder: A handbook for diagnosis and treatment 3 thed. New York: Guilford press; 2006.

4- Barkley RA. Behavioral inhibition sustained attention and executive functions constructing a unifying theory of ADHD. Psycol Bull1997; 121(1): 65-94.

5- Pennington BF, Ozonoff S. Executive functions and developmental psychology. J Child Psychol Psychiatry1996; 37: 51-87.

6- Sonaga-Barke EJ. Psychological heterogeneity in AD/ HD dual pathway model of behavior and cognition. Behav Brain Res2002; 130(1-2): 29-36.

7- Culbertson WC, Zillmer EA. The construct validity of the tower of London DX as a measure of the executive functioning of ADHD children. Assessment1998; 5(3): 215-26.

8- Coolidge FL, Thede LL, Young SE. Heritability and the comorbidity of attention deficit hyperactivity disorder with behavioral disorders and executive function deficits: A preliminary investigation. Dev Neuropsychol2000; 17(3): 273-87.

9- O'Driscoll GA, Depatie L, Holahanm ALV, et al. Executive functions and methylphenidate response in subtypes of attention deficit/ hyperactivity disorder. Biol Psychiat2005; 57(11): 1452-60.

10- Dawson P, Guare R. Executive skills in children and adolescents: A practical guide to assessment and intervention. New York: Guilford press; 2010.

11- Mashhadi A, Rasulzadeh Tabatabai K, Azadfallah C, Soltanifar AS. Planning and organization skills in children with attention deficit/hyperactivity disorder. Educational Studies and Psychology2010; 11(1): 170-51.

12- Gordon J, Vhang J. The ADD and ADHD cure. New Jersy: hobker; 2008.

13- Nigg JT. What causes ADHD? Understanding what goes wrong and why. NewYork: The Guilford press; 2006. 14- Barkley RA. Barkley functional impairment scalechildren and adolescents (BFIS-CA). New York: Guilford press; 2012.

15- Evans SW, Owens JS, Bunford N. Evidence-based psychosocial treatments for children and adolescents with attention-deficit/hyperactivity disorder. J Clin Child Adolesc Psychol2014; 43(4), 527-51.

16- Gillberg C. Deficits in attention, motor control, and perception: a brief review. Arch Dis Child2003; 88(10): 904-10.
17- Gray SA, Chaban P, Martinussen R, et al. Effects of a computerized working memory training program on working memory, attention, and academics in adolescents with severe LD and comorbid ADHD: a randomized controlled trial. $J$ Child Psychol Psychiatry2012; 53(12): 1277-84.

18- Beck SJ, Hanson CA, Puffenberger SS, Benninger KL, Benninger WB. A controlled trial of working memory training for children and adolescents with ADHD. J Clin Child Adolesc Psychol2010; 39(6): 825-36.

19- Ghomri Givi H, Narimani M, Mahmoudi H. Effectiveness cognitive advancing Software on executive function, response inhibition and working memory in children with dyslexia and attention deficit / hyperactivity. J Learn Disabil2012; 1(2): 98-115.

20- Posner MI, Rothbart MK. Influencing brain networks: Implications for education. Trends Cogn Sci2005; 9(3): 99-103.

21- Mashhadi A. Review of executive functions and the effectiveness of therapy (drug therapy, executive function training and combining these interventions) in executive functions and reduce the symptoms of children with attention deficit/Hyperactivity disorder. Tehran: Tarbiat Modarres University; 2009.

22- Ylvisaker M, Feeney J. Executive functions, Self-regulation, and Learned optimism in pediatric rehabilitation: a review and implications for intervention. Pediatr Rehabil2002; 5(2): 51-70.

23- Klingberg T, Fernel E, Olesen P, et al. Computerized training of working memory in children with ADHD- A randomized, controlled trial. J Am Acad Child Adolesc Psychiatry2005; 44(2): 177-86.

24-Saheban F, Amiri Sh, Kajbaf M, AbediA. Effectiveness of short-term training of executive functioning, on reduce symptoms of attention deficit and hyperactivity in elementary school students in Isfahan metropolitan. Advances in Cognitive Science2010; 12(1): 52-8.

25- Moradain Z. The effectiveness training of inhibition and planning-organizing executive functions in decrease of aggression \& ADHD symptoms in ADHD-C children. [Thesis]. Ferdowsi University of Mashhad, Mashhad, Iran, 2011.

26- Pliszka SL, Carlson CL, Swanson JM. ADHD with comorbid disorders clinical assessment and Management. New York: The Guilford press; 1999.

27- Sadralsadat J, Hoshyari Z, Zamani R, Sadralsadat L. Specification SNAP-IV scale psychometric rating, parent performance. Rehabilitation2007; 8(3): 59-65.

28- Rapoport EM. ADHD and social skills: A Step by Step Guide for Teachers and Parents. United states of America: Rowman and Littlefield Education; 2009.

\footnotetext{
Copyright $(\mathcal{C} 2016$ ASP Ins. This open-access article is published under the terms of the Creative Commons Attribution-NonCommercial 4.0 International License which permits Share (copy and redistribute the material in any medium or format) and Adapt (remix, transform, and build upon the material) under the Attribution-NonCommercial terms.
} 